\title{
AVALIAÇÃO DA ACESSIBILIDADE PARA IDOSOS EM APARTAMENTO DE ITAJUBÁ - MG
}

\section{Tamires Diniz Gomes ${ }^{1}$ \\ Cláudia Maria Alliprandini ${ }^{2}$}

Resumo: O processo de envelhecimento provoca a diminuição das funções biológicas do organismo, levando os idosos a enfrentar mais dificuldades na realização das suas atividades do dia a dia e serem mais sujeitos a sofrer quedas. Essas quedas acontecem por causa de pisos escorregadios e desnivelados, falta de rampas, falta de corrimãos. Dessa forma, a habitação dos idosos necessita ser adaptada, de maneira a ser acessível, confortável, e que os permita ser independentes. A avaliação da acessibilidade no apartamento e em sua rota acessivel se deu através da aplicação de um check list baseado na norma NBR 9050/2015. Desta forma, constatou-se que os maiores problemas se encontravam no apartamento e assim, foi desenvolvida uma planta modificada de maneira a contemplar totalmente a acessibilidade, para que assim os moradores idosos possam viver com mais qualidade de vida e conforto.

Palavras-chave: Idosos; Acessibilidade; Qualidade de vida; Ergonomia; Antropometria.

1 Graduanda em Engenharia Civil/FEPI - Centro Universitário de Itajubá, Brasil. E-mail: tatadinizgomes@hotmail.com.

2 Professora da FEPI - Centro Universitário de Itajubá/FEPI - Centro Universitário de Itajubá, Brasil. E-mail: alliprandiniarquitetura@gmail.com. 